\title{
Study on Local Water Culture Modeling Mechanism from the Perspective of Cultural Ecology: A Case Study of the Middle Yellow River Basin
}

\author{
Guan-yu Zhong ${ }^{1, a}$, Min Xiang ${ }^{1}$, Ming-dong Jiang ${ }^{1,2, b,}$, , \\ Hui Zhou ${ }^{3}$, Shao-xuan Zheng ${ }^{1}$, Lei Wang ${ }^{1}$ \\ ${ }^{1}$ School of Business Administration, Hohai University, Changzhou 213022, China
}

${ }^{2}$ Study and Research Group of The thought of socialism with Chinese characteristics in the new er a, Hohai University, Changzhou 213022, China

${ }^{3}$ College of Mechanical and Electrical Engineering, Hohai University,

Changzhou 213022, China

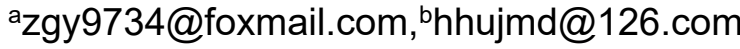

${ }^{*}$ Corresponding author

Keywords: Water culture, Cultural ecology, Cultural management.

\begin{abstract}
The Middle Yellow River Basin, as an important birthplace of Chinese culture, has an irreplaceable important position in the Chinese cultural landscape. It has created a splendid water culture represented by a self-reliant, hard-working culture and a pioneering and innovative culture. In the course of the formation and development of the water culture in the Middle Yellow River Basin, the material civilization and the ecological environment in the area were persistent to promote each other, and completed the self-enrichment and elevation of the local water culture. Such a molding mechanism continues to circulate in a cyclical manner, embodied in the history of farming civilization and commercial civilization in the Middle Yellow River Basin for more than two thousand years.
\end{abstract}

\section{Introduction}

Culture is a group of people in a certain geographical area. In a relatively long historical period, due to the continuous recognition, adaptation, utilization, and transformation of the ecological environment in which culture developed, the material civilizations that support its survival and development are produced and accumulated. A collection of self-recognition and reflections are consistent and inheritable within a group. The theory of cultural ecology is focused on elucidating the characteristics and types and origins of cultures under different geographical conditions, namely the interdisciplinary theory of how the human group's cultural approach uses the natural resources of the environment.

In terms of sociality, water culture is an important component of Chinese culture. Starting from the perspective of cultural ecology, the context of the origin and development of traceable culture can better clarify the overall mechanism of cultural generation and shaping. Cultural industry construction and cultural self-confidence construction work helped and inspired by it.

\section{Natural conditions in the Middle Yellow River Basin}

The Middle Yellow River Basin stretches from Hekou Town in the Toketo County of Inner Mongolia to Taohua Temple in Zhengzhou, Henan Province. The basin includes the four provinces of Inner Mongolia, Shaanxi, Shaanxi, and Henan. The watershed is distributed at $35^{\circ}-40^{\circ} \mathrm{N}$ latitude and is mainly temperate monsoon climate. The upper part is semi-arid, the lower part is semi-humid, and the precipitation is seasonal. The water vapor from the Pacific to the east is blocked by the Taihang Mountains. Precipitation in the basin is relatively small. The topography of the basin is dominated by plateaus and mountains, and there are basin plains between them. The overall terrain fluctuates greatly, and the water system is relatively numerous. 


\section{The Material Civilization in the Middle Yellow River Basin}

\subsection{The farming water civilization in the Middle Yellow River Basin}

The Weihe River Plain in the Middle Yellow River Basin is an important farming area in China since ancient times. The history of farming can be traced back to the Banpo civilization in the Neolithic Age. Since the Warring States Period, the Qin State, located on the Weihe River Plain, took the lead in promoting the feudal system of land reform, and implementing the private ownership system. When agriculture develops to a certain stage, the precipitation conditions brought about by the monsoon climate have become the decisive factor in the largest agricultural production. When the farming civilization develop to a certain stage, natural worship and religious ceremonies are no longer able to satisfy agricultural production. The strong demand for irrigation water, the construction of water conservancy facilities of various sizes, and the provision of irrigated agriculture as a form of farming civilization have become an inevitable requirement for the birth of this ecological environment. Therefore, a large number of water conservancy facilities were built during the Qin and Han dynasties in the middle Yellow River basin, and water conservancy facilities such as Zhengguo Canal, Chengguo Canal, Bai Canal, and Longshou Canal, which were mainly used for irrigation purposes, were built successively. Under the guarantee of multiple water conservancy facilities, over the past two thousand years, the continuous support of irrigated agriculture in the Weihe River Plain has supported a large number of agricultural population and developed an agrarian farming culture.

\subsection{Commercial Water Civilization in the Middle Yellow River Basin}

The undulating mountainous terrain in the Middle Yellow River Basin directly determine the traffic congestion between regions. The occluded regional interconnected conditions have affected the exchanges and the communication of commodities between regions, limiting the simple social division of labor based on the professional advantages of personnel and regional comparative advantages in the original farming states, and hindering the further development of agricultural civilization. On this basis, a further social division of labor has begun in the Middle Yellow River Basin Basin, and merchants specializing in the circulation and trafficking of labor products have emerged-Merchants from Shaanxi and Merchants from Shanxi have used waterways and transportion to access the region. The early commercial water civilization began. Afterwards, as the business community further conducted business across the country, it completed the initial accumulation of capital and created a financial institution with a capitalist nature - the ticket number. The bank's ticket number have turned out to be an outstanding financial innovation in seven aspects: organizational systems, financial instruments, business systems, financial risk management, fund operation information management, accounting system management, and personnel management. Its management system and management spirit are still up to today. It is a historic wealth with reference to contemporary business management.

\section{Local Water Culture in the Middle Yellow River Basin}

\subsection{A self-reliant, hard-working culture}

Irrigation agriculture is the most important form of social production in the Middle Yellow River Basin. The pillars stand for a solid foundation of a thousand years old. Whether it is a river course or a solid embankment, it is necessary to excavate and carry large amounts of rocks and mud. It all reflected the hardships of pioneering business. It was for two millennia that the river channels were continuously dredged, riverbanks were built, and generations of unnamed devotees were diverted into drainage canals. They struggled with the sand and struggled with the rocks. They made selfless dedication and perseverance. They used their firm soul of the Yellow River to harness and transform nature. Only for two thousand years, inexhaustible Guanzhong granaries had been formed, and a self-reliant and hardworking culture characterized by the Middle Yellow River Basin had been formed. 


\subsection{A pioneering and innovative culture}

The emphasis on agriculture and commerce is the basic national policy of China's feudal government that has remained unchanged for thousands of years under China's perennial small-scale peasant economic production system. Therefore, having the courage to find opportunities for sensitive sense of smell and create opportunities is the only way for Shaanxi businessmen and Shanxi merchants to seek space for development under the feudalism. By looking for business opportunities among different provinces, the communication of national tea, salt and minerals has accumulated a lot of original wealth. The great business chapter created by the original and leading ticket economy in the management system and operating system is also the best embodiment of the innovative culture that the people dares to take the lead of.

\section{Water Culture Modeling Mechanism in the Middle Yellow River Basin}

Ecological environment determines the form of early material civilization. The monsoon climate at mid-latitude brings changes to the precipitation pattern. The conditions of land and precipitation support the early development of farming civilization, and complete the agriculture in the earlier historical stages. The division of labor between farming, agriculture, and handicrafts constitutes a relatively complete system of early agricultural societies; macro and small areas are blocked by mountains and rivers, and natural resources that sufficiently supply local production and living in the early history are insufficient to support the further development of the region. The complete social system that was built earlier and completed gradually differentiates the division of professional businessmen to meet the demand for trade between regions. The primary products of farming civilization support the trade and development of commercial civilization among the regions.

In the course of the development of material civilization, because of the supports of ecological environment, material civilization has further recognized, developed, and reformed the ecological environment, and forced the ecological environment to create new requirements for material civilization. The development of farming civilization requires the construction of water conservancy facilities. And the construction of water conservancy facilities has provided more stable and controllable water resources for farming civilization, supporting the sustainable development of farming civilization; the development of commercial civilization has broadened the scope of its economic hinterland, accumulating A large amount of original capital has prompted it to develop new business models to support the new progress of commercial civilization.

\section{Acknowledgement}

This research was financially supported by the National Undergraduate Innovative Training Program: Cultivating and practicing socialist core values from the perspective of water culture and Hohai University Changzhou Campus Student Science and Technology Fund Project: Research on the Coupling Mechanism of Cultivating Socialist Core Values and Carrying Forward Chinese Water Culture.

Thanks Z. Li for her special support for this research.

\section{References}

[1] JH. Steward, Theory of Culture Change., University of Illinois Press Urbana, vol.07, pp.39-40,1979.

[2] Y. X., Guanzhong Water Conservancy in the Qin and Han Dynasties, Journal of Historical Science, vol.01, pp.112-114,1986. 